\title{
In vitro evaluation of the susceptibility of Acinetobacter baumannii isolates to antiseptics and disinfectants: comparison between clinical and environmental isolates
}

Sanae Lanjri , Jean Uwingabiye, Mohammed Frikh, Lina Abdellatifi, Jalal Kasouati, Adil Maleb, Abdelouahed Bait, Abdelhay Lemnouer and Mostafa Elouennass

\begin{abstract}
Background: This study aims to assess the susceptibility of Acinetobacter baumannii isolates to the antiseptics and disinfectants commonly used, and to the non-approved product.

Methods: This is a prospective study carried out from February to August 2015, in the Bacteriology department of Mohammed V Military Teaching hospital of Rabat on A.baumannii isolates collected from colonized and/or infected patients and environmental samples. The antiseptics and disinfectants susceptibility testing was assessed using the micromethod validated in our department. The antiseptics and disinfectants studied were: $70 \%$ ethyl alcohol, chlorhexidine, povidone-iodine, didecyldimethylammonium chloride and a commercial product which was presented as a hospital disinfectant (non-registered product).

Results: Povidone-iodine, $0.5 \%$ chlorhexidine digluconate, $70 \%$ ethyl alcohol and didecyl dimethyl ammonium chloride in combination with $\mathrm{N}$ - (3-aminopropyl) - N-dodecylpropane-1, 3-diamine were effective against all the 81 A.baumannii isolates tested, and their logarithmic reduction $\geq 5$ were observed in $100 \%$ of the isolates in their undiluted form. The strains isolated from patients were more resistant than environmental strains: at a dilution of $1 / 2$ for $70 \%$ ethyl alcohol (37. $77 \%$ vs $11.11 \%, p=0.007)$ and at a dilution of $1 / 10(100 \%$ vs $69.44 \%, p<0.001)$ for povidone iodine. The non-registered product was ineffective with a resistance rate of $96.29 \%$ at a dilution of $1 / 50,45.67 \%$ at a dilution of $1 / 10$ and $13.58 \%$ in its purest form.

Conclusion: Our study revealed the effectiveness of the main disinfectants and antiseptics used in Morocco; three antiseptics tested were effective in their purest form against the 81 A.baumannii isolates. Regarding disinfectants, our results showed an efficacy of didecyl dimethyl ammonium at the recommended use concentration and in its purest form. This study emphasizes the need for using disinfectants and antiseptics in dilutions recommended by the manufacturer because the insufficient dilutions of these products are not effective. Our findings also demonstrated an inefficiency of the non-registered product against A.baumanii isolates. However, the non-registered products should be prohibited.
\end{abstract}

Keywords: Acinetobacter baumannii, Resistance, Antiseptics, Disinfectants

\footnotetext{
* Correspondence: lanjrisanae@gmail.com

Department of Clinical Bacteriology, Mohammed V Military teaching hospital, research team of Epidemiology and Bacterial resistance, Faculty of Medicine and Pharmacy, Mohammed V University, Rabat, Morocco
} 


\section{Background}

Acinetobacter baumannii is a Gram-negative bacillus that has emerged in recent years as one of the pathogens that poses the most problems of antibiotic resistance, morbidity and mortality in health facilities worldwide [1].

A.baumannii is a ubiquitous bacterium that can be isolated from both the environment [2] and the human's skin [3, 4]. It mainly affects debilitated patients [5] and it is responsible for a variety of life-threatening infections including bacteremia and pneumonia [1]. In an American study, 5 to $10 \%$ of nosocomial pneumonia and $1.3 \%$ of bacteremia were due to A. baumannii $[6,7]$. In a Moroccan study published in 2016, Acinetobacter spp. isolates represented $6.94 \%$ of all bacterial clinical isolates and $9.6 \%$ of Gram negative rods [8].

The remarkable ability of A.baumannii to easily acquire resistance factors ranked it among the organisms that threaten the current therapeutic armamentarium. A. baumannii strain resistant to all known antibiotics has already been reported in France [9]. The Moroccan studies showed that the resistance rate to imipenem, ceftazidime, amikacin and ciprofloxacin increased from 23 to $76 \%, 63$ to $86 \%, 41$ to $52 \%$ and 68 to $87 \%$ respectively during the last 13 years $[8,10]$.

The importance of hand transmission in the spread of this bacteria and prolonged survival in the environment (>8 days) complicates the prevention and control of these infections [1]. Indeed, hand hygiene and environmental cleanliness are the keystone of the infection control measures for the prevention of the spread of A.bauamannii. The use of antiseptics and disinfectants is an important means in these infection control strategies. Their use allows the reduction or elimination of bacterial reservoir and prevents the transition from colonization to infection [11].

Contrary to antibiotics, studies that have been devoted to the emergence of $A$. baumannii resistant to antiseptics and disinfectants are very few. Some emphasize the increase in resistance rates to these products. A study assessing the susceptibility of 445 bacterial strains from various genera against more than 50 types of disinfectants revealed that $A$. baumannii isolates were the most resistant species. Resistance rates were higher against oxidizing agents while the lowest resistance rate was observed against quaternary ammonium compounds and amines [12].

Antiseptic resistance rates vary. One study showed that on hands artificially contaminated with A. baumannii, ethyl alcohol and povidone-iodine had higher removal ratio than chlorhexidine and ordinary soap [13].

The aim of our study was to assess the susceptibility of $A$. baumannii strains to the antiseptics and disinfectants commonly used, and to a non-registered product.

\section{Methods}

\section{Type of the study}

This is a prospective study performed in the Bacteriology department of Mohammed V Military Teaching hospital (HMIMV) of Rabat from February to August 2015. HMIMV has a hospital capacity of more than 700 beds and contains 2 intensive care units (medical and surgical) with 10 beds each, a center for burns treatment, surgical and medical units, and laboratory and imagery departments.

\section{Bacterial isolates}

The A. baumannii strains tested were isolated from colonized and/or infected patients, and environmental samples in the HMIMV.

In addition to these isolates, a reference strain was tested (Escherichia coli ATCC $^{\oplus} 25922^{\mathrm{min}}$ ).

\section{Antiseptics and disinfectants tested}

In our institution, the antiseptics mainly used are polividone iodine and chlorhexidine. For the bio-cleaning of floors and surfaces, the disinfectant used is didecyl dimethyl ammonium chloride.

During our study, five products were tested including three antiseptics and two disinfectants including a commercial detergent-disinfectant whose composition is unknown (Table 1).

\section{Methods}

The sensitivity of A.baumannii isolates to antiseptics and disinfectants was assessed using the microdilution method (micromethod), validated in our laboratory.

The validation of our method was made by comparing its results with those obtained by the tube dilution method (macromethod) for three isolates to Surfanios ${ }^{\oplus}$, as it was described by Mama et al. (2014) [14].

\section{Validation of a micromethod for the determination of the susceptibility to antiseptics and disinfectants Inoculum preparation}

After thawing the bacterial isolates to be tested, a brain heart broth was inoculated and incubated at $37^{\circ} \mathrm{C}$ for 18 to $24 \mathrm{~h}$. The broths were subsequently subcultured on blood agar and incubated at $37^{\circ} \mathrm{C}$ for 18 to $24 \mathrm{~h}$. The inoculum was prepared by saline suspension of isolated colonies selected from an 18 to $24 \mathrm{~h}$ agar plate. The turbidity of these suspensions was adjusted to. 0.5 McFarland standard.

\section{Dilution of the initial inoculum}

After calculating the different volumes to be used for the micromethod by respecting the proportions used in the macromethod, the volume of the bacterial suspension was found very low $(1 \mu \mathrm{l})$. To increase the volume, 1/10 
Table 1 The recommended dilutions, abbreviation, active ingredient and the dilutions tested for each product in our study

\begin{tabular}{|c|c|c|c|c|}
\hline Product & Abbreviation & Active ingredient & $\begin{array}{l}\text { Recommended } \\
\text { dilutions }\end{array}$ & dilutions tested \\
\hline Betadine scrub ${ }^{\oplus}$ & PVPI & $4 \%$ povidone-iodine & Pure, $1 / 3$ & pure, $1|3,1| 10,1|100,1| 1000$ \\
\hline septeal ${ }^{\oplus}$ & $\mathrm{CHX}$ & 0.5\% chlorhexidine digluconate & Pure & pure, $1|10,1| 100,1 \mid 1000$ \\
\hline ethyl alcohol 70 & $\mathrm{AL}$ & $70 \%$ ethyl Alcohol & Pure & pure, $1|2,1| 10,1|100,1| 1000$ \\
\hline Surfanios ${ }^{\circledast}$ & DDA & $\begin{array}{l}\text { N- (3-aminopropyl) -N-dodécylpropane-1, } \\
\text { 3-diamine }(51 \mathrm{mg} / \mathrm{g})+ \\
\text { didecyl dimethyl ammonium chloride } \\
(25 \mathrm{mg} / \mathrm{g})\end{array}$ & $1 \mid 400(0,25 \%)$ & $\begin{array}{l}\text { pure, } 1|10,1| 100,1|200,1| 400 \\
1|1000,1| 10000,1 \mid 1000000\end{array}$ \\
\hline Non registered product & NRP & unknown composition & $1 \mid 50(2 \%)$ & pure, $1|10,1| 50,1|100,1| 1000$ \\
\hline
\end{tabular}

dilution of the previously standardized bacterial suspension at 0.5 McFarland was performed.

\section{Preparation of antiseptic and disinfectant solutions}

The different prepared dilutions of each product were chosen according to the concentration recommended by the manufacturer (Table 1).

\section{Validation tests \\ Macromethod validation}

In a sterile test tube, $4.9 \mathrm{ml}$ of sterile trypticase soy broth was mixed with $5 \mathrm{ml}$ of each dilution of the antimicrobial agent. To obtain a final volume of $10 \mathrm{ml}, 0.1 \mathrm{ml}$ of standardized bacterial suspension was inoculated into each tube.

Two control tubes were used; positive control tube containing only the nutrient broth and the strain to be tested, while negative controls were established as follows: nutrient broth only, nutrient broth and antimicrobial agent.

After $24 \mathrm{~h}$ at $37^{\circ} \mathrm{C}$, the visible signs of bacterial growth (turbidity) were not possible to detect given the macroscopic qualities of the product-broth mixture in all the tubes including the control tubes. All tubes were then subcultured on Bromocresol Purple (BCP) agar and incubated at $37{ }^{\circ} \mathrm{C}$ for $24 \mathrm{~h}$. The reading of each culture plate has been validated by the absence of growth in sterility control wells and bacterial growth in fertility control wells.

\section{Micromethod validation, and antiseptics and disinfectants susceptibility testing}

The wells of a microplate were filled with appropriate volumes of increasing concentrations of antiseptic or disinfectant solution and then completed with corresponding volumes of broth and suspension of the inoculum.

In practice, each well of a sterile 96-well plate was inoculated with $50 \mu \mathrm{l}$ of dilution of the antimicrobial agent, $40 \mu \mathrm{l}$ of trypticase soy and $10 \mu \mathrm{l}$ of diluted bacterial suspension.

The positive control wells were inoculated with $40 \mu \mathrm{l}$ of nutrient broth and $10 \mu \mathrm{l}$ of the bacterial suspension (fertility testing), while the negative controls were inoculated with nutrient broth and the antimicrobial agent (sterility testing).

After $24 \mathrm{~h}$ at $37^{\circ} \mathrm{C}$, all tubes were then subcultured on $\mathrm{BCP}$ agar and incubated at $37{ }^{\circ} \mathrm{C}$ for $24 \mathrm{~h}$. Reading of agar plates was performed as described in macromethod validation.

The macromethod was used as reference for validating the micromethod, with both methods leading to the same results.

The evaluation of the A. baumanni susceptilibity to antiseptics and disinfectants was realized by using micromethod as it was described in the validation's paragraph. The number of colony-forming units was counted on each plate. The plates on which manual counting of bacterial colony-forming units was not possible, the number of colony-forming unit was considered to be above $10^{7}$.

The rate of the log reduction of the different products was calculated. The $\geqslant 5 \log 10$ reduction was considered as significant reduction of growth.

\section{Statistical analysis}

Statistical analysis was performed using SPSS statistical software version 13.0 and Microsoft Office Excel 2007. Susceptibility comparisons of the isolates from the patient and environmental samples to different products were established using the chi test-square. $P$ values less than 0.05 were considered statistically significant.

\section{Results}

During this study, 81 A.baumannii isolates were tested: 45 strains from patient samples and 36 strains from the environmental samples. The majority of clinical isolates were predominantly collected from intensive care unit's (ICUs) patients $(n=34,75.5 \%)$, followed by those from medical department $(n=8,17.8 \%)$ and external consultants $(n=3,6.7 \%)$. Of the clinical isolates, $23(51.1 \%)$ were colonizing isolates and $22(48.9 \%)$ were infectious ones. The colonizing isolates were isolated from anal margin (43.5\%), groin area $(8.34 .8 \%)$ and mouth (n21.7\%), while the isolation sites of infectious isolates were: broncho-pulmonary (45.5\%), urine (31.8\%) and 
blood culture (13.6\%), catheters (4.5\%), joint fluid (4.5\%) and cutaneous lesions (4.5\%). The environmental isolates were exclusively recovered from the ICUs. The distribution of isolation sites for environmental isolates was: bed sheets (38.9\%), soil (36.1\%), hospital respirators (11.1\%), trolleys $(5.6 \%)$, gallows $(2.8 \%)$, pillows $(2.8 \%)$ and monitors $(2.8 \%)$.

All chemical agents tested were found to be effective on the Escherichia coli ATCC 25922 reference strain in their purest form (Table 2).

The Tables 3 and 4 represent respectively the resistance rates of A.baumannii strains and the logarithmic reduction $\geq 5$ over the initial time zero inoculum levels of the various products tested. Povidone-iodine, $0.5 \%$ chlorhexidine digluconate, $70 \%$ ethyl alcohol and didecyl dimethyl ammonium chloride in combination with $\mathrm{N}$ (3-aminopropyl) -N-dodecylpropane-1, 3-diamine were effective against all the 81 A.baumannii isolates tested and their logarithmic reduction $\geq 5$ was observed in $100 \%$ of isolates in their undiluted form. The strains isolated from patients were more resistant than environmental strains: at a dilution of $1 / 2$ for70 \% ethyl alcohol (37.77\% vs $11.11 \%$ and $p=0.007$ ) and at a dilution of $1 /$ $10(100 \%$ vs $69.44 \%, p<0.001)$ for povidone iodine. The

Table 2 Efficacy of antiseptics and disinfectants tested on Escherichia coli ATCC ${ }^{\circledR} 25922^{\mathrm{TM}}$ reference strain

\begin{tabular}{|c|c|c|}
\hline Product & Dilution & Bacterial growth \\
\hline \multirow[t]{4}{*}{ PVPI } & PURE & - \\
\hline & $1 \mid 3$ & - \\
\hline & $1 \mid 10$ & + \\
\hline & $1|100,1| 1000$ & + \\
\hline \multirow[t]{4}{*}{$\mathrm{CHX}$} & PURE & - \\
\hline & $1 \mid 10$ & - \\
\hline & $1 \mid 100$ & - \\
\hline & $1 \mid 1000$ & + \\
\hline \multirow[t]{4}{*}{$\mathrm{AL}$} & PURE & - \\
\hline & $1 \mid 2$ & + \\
\hline & $1 \mid 10$ & + \\
\hline & $1|100,1| 1000$ & + \\
\hline \multirow[t]{4}{*}{ DDA } & PURE, $1|10,1| 100,1 \mid 400$ & - \\
\hline & $1 \mid 1000$ & - \\
\hline & $10-4$ & + \\
\hline & $10-5,10-6$ & + \\
\hline \multirow[t]{4}{*}{ NRP } & PURE & - \\
\hline & $1 \mid 10$ & + \\
\hline & $1 \mid 50$ & + \\
\hline & $1|100,1| 1000$ & + \\
\hline
\end{tabular}

PVPI povidone-iodine, $C H X$ chlorhexidine digluconate, $A L$ ethyl Alcohol, DDA N(3-aminopropyl)-N-dodécylpropane-1,3-diamine + didecyl dimethyl ammonium chloride, NRP non registered product, (+) Growth, (-) No growth non-registered product was ineffective with resistant rate of $96.29 \%$ at a dilution of $1 / 50,45.67 \%$ at a dilution of $1 /$ 10 and $13.58 \%$ in its purest form.

\section{Discussion}

Our study was focused on three commonly used antiseptics: $70 \%$ ethyl alcohol, chlorhexidine and povidoneiodine, on a disinfectant (didecyldimethylammonium chloride) and on a commercial product which was presented as a hospital disinfectant.

The $70 \%$ ethyl alcohol is used for antisepsis of small superficial wounds and skin before an injection. It's a component of several hand sanitizers. Other alcohols, such as propanol and isopropanol, are also used as hand sanitizers [11]. In our study, pure ethyl alcohol (70\%) was effective against all A.baumannii isolates. At a dilution of $1 / 2$, the resistance rate was $25.92 \%$. The strains isolated from patients were more resistant than environmental strains $(37.77 \%$ vs $11,11 \%, p=0.007)$. The $\geqslant 5$ $\log 10$ reduction was obtained in $100 \%$ of isolates at undiluted state, in $74 \%$ at dilution of $1 / 2$ and in $12.34 \%$ at dilution of $1 / 10$. Wisplinghoff et al. [15] used $60 \%$ propanol and found the results similar to ours while the contact time was $15 \mathrm{~s}, 30 \mathrm{~s}, 60 \mathrm{~s}$ and $120 \mathrm{~s}$.

The $0.5 \%$ chlorhexidine digluconate is recommended in antisepsis of surgical wounds, common skin infections, and antisepsis of healthy skin prior to minor surgery. It is applied to the skin without rinsing [11]. In our study, chlorhexidine at its undiluted state has shown its effectiveness against all 81 isolates tested. The logarithmic reduction $\geq 5$ was observed in $100 \%$ of isolates in its undiluted state and in $92.59 \%$ of isolates at a dilution of $1 / 10$. The difference in resistance rates between isolates from the patient and the environmental samples was not significant. Comparing these rates with those of $70 \%$ ethyl alcohol, the chlorehexidine is more effective. Our results agree with Wisplinghoff et al's study [15]. Another study showed that daily bathing with chlorhexidine $2 \%$ in the ICU reduced the rate of acquisition of A.baumannii isolates resistant to carbapenems by $51.8 \%$ [16].

The povidone iodine is a foam solution composed of iodine and is used for scrubbing, antisepsis of healthy skin, preoperative shower; for which, it should be used in its purest form. For the cleansing of contaminated wounds, it is recommended that one-third be diluted with water [11]. In our study, all isolates were sensitive to pure povidoneiodine. While at the dilution of $1 / 3$ (dilution recommended for cleansing of wounds), $18.51 \%$ isolates were resistant. In Povidone Iodine's purest form and at a dilution of $1 / 3$, the difference in resistance rates between isolates from patients and the environmental isolates was not significant. Clinical strains were more resistant than the environmental strains at a dilution of $1 / 10(100 \%$ vs $69.44 \%, p<0.05)$. The logarithmic reduction $\geq 5$ was observed in $100 \%$ in its 
Table 3 Comparison of resistance rates between A.baumannii strains isolated from patients and from environmental samples to different products tested

\begin{tabular}{|c|c|c|c|c|c|}
\hline \multirow[t]{2}{*}{ Products } & \multirow[t]{2}{*}{ Dilution } & \multicolumn{2}{|c|}{ Origin of the strains } & \multirow{2}{*}{$\begin{array}{l}\text { Total } \\
(n=81)\end{array}$} & \multirow[t]{2}{*}{$P$} \\
\hline & & Patients $(n=45)$ & Environment $(n=36)$ & & \\
\hline \multirow[t]{4}{*}{ PVPI } & PURE & $0 \%(0)$ & $0 \%(0)$ & $0 \%(0)$ & - \\
\hline & $1 \mid 3$ & $24.44 \%(11)$ & $11.11 \%(4)$ & $18.51 \%(15)$ & 0.125 \\
\hline & $1 \mid 10$ & $100 \%(45)$ & $69.44 \%(25)$ & $86.41 \%(70)$ & $<0.001$ \\
\hline & $1|100,1| 1000$ & $100 \%(45)$ & $100 \%(36)$ & $100 \%(81)$ & - \\
\hline \multirow[t]{4}{*}{$\mathrm{CHX}$} & PURE & $0 \%(0)$ & $0 \%(0)$ & $0 \%(0)$ & - \\
\hline & $1 \mid 10$ & $13.33 \%(6)$ & $0 \%(0)$ & $7.40 \%(6)$ & 0.31 \\
\hline & $1 \mid 100$ & $51.11 \%(23)$ & $66.66 \%(24)$ & $58.02(47)$ & 0.159 \\
\hline & $1 \mid 1000$ & $100 \%(45)$ & $100 \%(36)$ & $100 \%(81)$ & - \\
\hline \multirow[t]{4}{*}{ AL } & PURE & $0 \%(0)$ & $0 \%(0)$ & $0 \%(0)$ & - \\
\hline & $1 \mid 2$ & $37.77 \%(17)$ & $11.11 \%(4)$ & $25.92 \%(21)$ & 0.007 \\
\hline & $1 \mid 10$ & $93.33 \%(42)$ & $80.55 \%(29)$ & $87.65 \%(71)$ & 0.100 \\
\hline & $1|100,1| 1000$ & $100 \%(45)$ & $100 \%(36)$ & $100 \%(81)$ & - \\
\hline \multirow[t]{4}{*}{ DDA } & PURE, 1|10,1|100, 1|400 & $0 \%(0)$ & $0 \%(0)$ & $0 \%(0)$ & - \\
\hline & $1 \mid 1000$ & $24.44 \%(11)$ & $8.33 \%(3)$ & $17.28 \%(14)$ & 0.057 \\
\hline & $10-4$ & $86.66 \%(39)$ & $69.44 \%(25)$ & $79.01 \%(64)$ & 0.059 \\
\hline & $10-5,10-6$ & $100 \%(45)$ & $100 \%(36)$ & $100 \%(81)$ & - \\
\hline \multirow[t]{4}{*}{ NRP } & PURE & $24.44 \%(11)$ & $0 \%(0)$ & $13.58 \%(11)$ & 0.001 \\
\hline & $1 \mid 10$ & $66.66 \%(30)$ & $19.44 \%(7)$ & $45.67 \%$ (37) & $<0.001$ \\
\hline & $1 \mid 50$ & $97.77 \%(44)$ & $94.44 \%(34)$ & $96.29 \%(78)$ & 0.582 \\
\hline & $1|100,1| 1000$ & $100 \%(45)$ & $100 \%(36)$ & $100 \%(81)$ & - \\
\hline
\end{tabular}

PVPI povidone-iodine, CHX chlorhexidine digluconate, AL ethyl Alcohol, DDA N-(3-aminopropyl)-N-dodécylpropane-1,3-diamine + didecyl dimethyl ammonium chloride, NRP non registered

$-: p$ value not calculated

purest form, in $81.48 \%$ at the dilution of $1 / 3$ and in $13.58 \%$ at a dilution of $1 / 10$. In the study conducted by Wisplinghoff et al [15], pure povidone iodine was active against all Acinetobacter isolates tested.

Environmental hygiene plays an important role in cross-transmission of $A$. baumannii. Prolonged survival of A.baumannii in a dry environment has been correlated with ongoing epidemics in ICUs [17]. During an $A$. baumannii outbreak which occurred over a period of 14 months in a neurosurgery ICU in the United Kingdom, a significant correlation was observed between the number of infected or colonized patients and the number of environmental isolates $(p=0.004)$ [18]. The majority of detergent-disinfectants for floors and surfaces are composed of quaternary ammonium compounds only [19] or associated with other substances (Biguanide derivatives, aldehydes, isopropanol, alkylamine, amino acid, hydrogen peroxide, ethanol ...). Some studies reported acquired resistance to quaternary ammonium compounds, and that these products have a higher effectiveness against Gram-positive bacteria than against Gram-negative bacteria [11, 20]. Didecyldimethylammonium chloride in association with the amino acid hydrochloride (Surfanios ${ }^{\odot}$ ) is used in the hospital, diluted to $0.25 \%(1 / 400)$ according to the manufacturer's recommendations, for the biocleaning of floors and surfaces. In our study, Surfanios ${ }^{\oplus}$ was effective against all isolates at the recommended dilution (1/400). Resistance was observed at a dilution of $1 / 1000$ with a rate of $17.28 \%$. There was no significant difference in resistance between the clinical and environmental isolates. In the study of Reichel et al [21], three Quaternary ammonium compound products were effective against three A. baumannii strains.

Another product tested in this study, is presented as a hospital-level disinfectant and its composition is unknown (non-registered product). The concentration recommended by the manufacturer is $2 \%(1 / 50)$. This product was ineffective with resistance rate of $96.29 \%$ at a dilution of $1 / 50,45.67 \%$ at a dilution of $1 / 10$ and $13.58 \%$ in its purest form. Our results show the ineffectiveness of this product and emphasize the advantage of using the products inscribed on the positive lists published by learned societies. The right choice of antiseptics and disinfectants plays a crucial role in preventing the development of resistance. 
Table 4 The rate of isolates presenting logarithmic reduction $\geq 5$ from initial inoculum

\begin{tabular}{|c|c|c|}
\hline Product & Dilution & The rate of isolates presenting logarithmic $\geq 5 \log _{10}$ reduction \\
\hline \multirow[t]{4}{*}{ PVPI } & PURE & $100 \%$ \\
\hline & $1 \mid 3$ & $81.48 \%$ \\
\hline & $1 \mid 10$ & $13.58 \%$ \\
\hline & $1|100,1| 1000$ & $0 \%$ \\
\hline \multirow[t]{4}{*}{$\mathrm{CHX}$} & PURE & $100 \%$ \\
\hline & $1 \mid 10$ & $92.59 \%$ \\
\hline & $1 \mid 100$ & $41.97 \%$ \\
\hline & $1 \mid 1000$ & $0 \%$ \\
\hline \multirow[t]{4}{*}{ AL } & PURE & $100 \%$ \\
\hline & $1 \mid 2$ & $74.07 \%$ \\
\hline & $1 \mid 10$ & $12.34 \%$ \\
\hline & $1|100,1| 1000$ & $0 \%$ \\
\hline \multirow[t]{4}{*}{ DDA } & PURE, 1|10, 1|100, 1|400 & $100 \%$ \\
\hline & $1 \mid 1000$ & $82.71 \%$ \\
\hline & $10-4$ & $20.98 \%$ \\
\hline & $10-5,10-6$ & $0 \%$ \\
\hline \multirow[t]{4}{*}{ NRP } & PURE & $86.4 \%$ \\
\hline & $1 \mid 10$ & $54.32 \%$ \\
\hline & $1 \mid 50$ & $3.70 \%$ \\
\hline & $1|100,1| 1000$ & $0 \%$ \\
\hline
\end{tabular}

PVPI povidone-iodine, $C H X$ chlorhexidine digluconate, $A$ L ethyl Alcohol, DDA N-(3-aminopropyl)-N-dodécylpropane-1,3-diamine + didecyl dimethyl ammonium chloride, NRP non registered product

Globally, the clinical isolates were more resistant to the antiseptics and disinfectants in their diluted state than the environmental ones. This shows that the minimum inhibitory concentrations of clinical and those of environmental isolates to biocides are not the same. The colonizing and infecting A.baumannii isolates were the most resistant to the antiseptics and disinfectants. This can probably be explained by the selection pressure exerted by the use of antiseptics and sometimes facilitated by the sub-inhibitory concentrations [22].

\section{Conclusion}

Our study revealed the effectiveness of the main disinfectants and antiseptics used in Morocco: three antiseptics tested were effective in their purest form against the 81 A.baumannii isolates. However, with povidone iodine diluted at one third, $18.51 \%$ of isolates were resistant. Regarding disinfectants, our results showed an efficacy of Didecyldimethylammonium at the recommended concentration. This study emphasizes the need for using disinfectants and antiseptics in dilutions recommended by the manufacturer because the insufficient concentrations of these products are ineffective. Our findings also demonstrated an inefficiency of the non-registered product against Acinetobacter isolates. The market for these products is constantly increasing but it is potentially associated with risks. Therefore, a regulatory framework for the use of these products must be implemented both for hospital and community use.

\section{Abbreviations}

A.baumannii: Acinetobacter baumannii; AL: Ethyl alcohol; BCP: Bromocresol purple; CHX: Chlorhexidine digluconate; DDA: N-(3-aminopropyl)-Ndodécylpropane-1,3-diamine + didecyl dimethyl ammonium chloride; HMIMV: Mohammed V military teaching hospital of Rabat; ICUs: Intensive care units; NRP: Non registered; PVPI: Povidone-iodine

\section{Acknowledgements}

Not applicable.

\section{Funding}

No external funding was received for this study.

\section{Availability of data and materials}

All data analyzed during this study are included in this published article.

Authors' contributions

$S L, U J$ and ME designed the study, collected data and wrote the manuscript. $M F, A L$ and $L A$ were involved in the review of literature, $A B$ and $A M$ provided critical revision of the manuscript. JK participated in statistical analysis. All authors contributed to the interpretation of the results, the revision of the draft manuscript and approval of the final version.

Competing interests

The authors declare that they have no competing interests. 


\section{Consent for publication}

Not applicable.

\section{Ethics approval and consent to participate}

This study does not constitute human research requiring Institutional Review Board approval.

\section{Publisher's Note}

Springer Nature remains neutral with regard to jurisdictional claims in published maps and institutional affiliations.

Received: 21 December 2016 Accepted: 6 April 2017

Published online: 11 April 2017

\section{References}

1. Peleg AY, Seifert H, Paterson DL. Acinetobacter baumannii: emergence of a successful pathogen. Clin Microbiol Rev. 2008;21(3):538.

2. Fournier PE, Richet $\mathrm{H}$. The epidemiology and control of Acinetobacter baumannii in health care facilities. Clin Infect Dis. 2006:42(5):692-9.

3. Seifert H, Dijkshoorn L, Gerner-Smidt P, Pelzer N, Tjernberg I, Vaneechoutte M. Distribution of Acinetobacter species on human skin: comparison of phenotypic and genotypic identification methods. J Clin Microbiol. 1997;35:2819-25.

4. Berlau J, Aucken H, Malnick H, Pitt T. Distribution of Acinetobacter species on skin of healthy humans. Eur J Clin Microbiol Infect Dis. 1999;18(3):179-83.

5. Bergogne-Bérézin E, Towner KJ. Acinetobacter spp. as nosocomial pathogens: microbiological, clinical, and epidemiological features. Clin Microbiol Rev. 1996;9(2):148-65.

6. Gaynes R, Edwards JR, National Nosocomial Infections Surveillance System. Overview of nosocomial infections caused by gram-negative bacilli. Clin Infect Dis. 2005;41:848-54.

7. Wisplinghoff $H$, Bischoff $T$, Tallent SM, Seifert $H$, Wenzel RP, Edmond MB Nosocomial bloodstream infections in US hospitals: analysis of 24,179 cases from a prospective nationwide surveillance study. Clin Infect Dis. 2004;39:309-17.

8. Uwingabiye J, Frikh M, Lemnouer A, Bssaibis F, Belefquih B, Maleb A, Dahraoui S, Belyamani L, Bait A, Haimeur C, Louzi L, Ibrahimi A, Elouennass M. Acinetobacter infections prevalence and frequency of the antibiotics resistance: comparative study of intensive care units versus other hospital units. Pan Afr Med J. 2016;23:191.

9. Rolain JM, Roch A, Castanier M, Papazian L, Raoult D. Acinetobacter baumannii resistant to colistin with impaired virulence: a case report from France. J Infect Dis. 2011;204:1146-7.

10. Elouennass M, Bajou T, Lemnouer AH, Foissaud V, Hervé V, Baaj AJ. Acinetobacter baumannii : étude de la sensibilité des souches isolées à I'hôpital militaire d'instruction Mohammed V, Rabat. Maroc Med Mal Infect. 2003:33:361-4.

11. Boyce JM, Pittet D, Healthcare Infection Control Practices Advisory Committee, HICPAC/SHEA/APIC/IDSA Hand Hygiene Task Force. Guideline for hand hygiene in health-care settings. Recommendations of the Healthcare Infection Control Practices Advisory Committee and the HICPAC/SHEA/APIC/IDSA Hand Hygiene Task Force. Society for Healthcare Epidemiology of America/ Association for Professionals in Infection Control/Infectious Diseases Society of America. MMWR Recomm Rep. 2002;51(RR-16):1-45.

12. Saperkin N, Kovalishena O, Blagonravova A. P089: surveillance of bacterial resistance to disinfectants. Antimicrob Resist Infect Control. 2013;2 Suppl 1:89.

13. Cardoso $\mathrm{CL}$, Pereira HH, Zequim JC, Guilhermetti M. Effectiveness of handcleansing agents for removing Acinetobacter baumannii strain from contaminated hands. Am J Infect Control. 1999;27:327-31.

14. Mama M, Abdissa A, Sewunet T. Antimicrobial susceptibility pattern of bacterial isolates from wound infection and their sensitivity to alternative topical agents at Jimma University specialized hospital, South-West Ethiopia. Ann Clin Microbiol Antimicrob. 2014;13:14.

15. Wisplinghoff $H$, Schmitt $R$, Wöhrmann A, Stefanik D, Seifert $H$. Resistance to disinfectants in epidemiologically defined clinical isolates of Acinetobacter baumannii. J Hosp Infect. 2007;66(2):174-81.

16. Chung YK, Kim JS, Lee SS, Lee JA, Kim HS, Shin KS, Park EY, Kang BS, Lee HJ, Kang HJ. Effect of daily chlorhexidine bathing on acquisition of carbapenemresistant Acinetobacter baumannii (CRAB) in the medical intensive care unit with CRAB endemicity. Am J Infect Control. 2015:43(11):1171-7.

17. Catalano M, Quelle LS, Jeric PE, Di Martino A, Maimone SM. Survival of Acinetobacter baumannii on bed rails during an outbreak and during sporadic cases. J Hosp Infect. 1999;42:27-35.
18. Denton M, Wilcox MH, Parnell P, Green D, Keer V, Hawkey PM, Evans I, Murphy $P$. Role of environmental cleaning in controlling an outbreak of Acinetobacter baumannii on a neurosurgical intensive care unit. J Hosp Infect. 2004:56:106-10.

19. Smith K, Gemmell CG, Hunter IS. The association between biocide tolerance and the presence or absence of qac genes among hospital-acquired and community-acquired MRSA isolates. J Antimicrob Chemother. 2008;61(1):78-84.

20. Block BB. Peroxygen compounds. In: Block SS, editor. Disinfection, sterilization, and preservation. 4th ed. Philadelphia, Pa, USA: Lea \& Febiger; 1991. p. 167.

21. Reichel M, Schlicht A, Ostermeyer C, Kampf G. Efficacy of surface disinfectant cleaners against emerging highly resistant gram-negative bacteria. BMC Infect Dis. 2014;14:292.

22. Gilbert P, McBain AJ. Potential impact of increased use of biocides in consumer products on prevalence of antibiotic resistance. Clin Microbiol Rev. 2003;16(2):189-208.

\section{Submit your next manuscript to BioMed Central and we will help you at every step:}

- We accept pre-submission inquiries

- Our selector tool helps you to find the most relevant journal

- We provide round the clock customer support

- Convenient online submission

- Thorough peer review

- Inclusion in PubMed and all major indexing services

- Maximum visibility for your research

Submit your manuscript at www.biomedcentral.com/submit
Ciomed Central 